\title{
Short communication: Lactose utilization of Streptococcus thermophilus and correlations with $\beta$-galactosidase and urease
}

\author{
Peng Yu, ${ }^{1}$ Nan $\mathrm{Li}^{2}{ }^{2}$ Mingxue Geng, ${ }^{1}$ Zhenmin Liu, ${ }^{2 *}$ Xiaoming Liu, ${ }^{3,4 *} \oplus$ Heping Zhang ${ }^{5}$ Jianxin Zhao, ${ }^{1,3,4}$ \\ Hao Zhang, ${ }^{1,3,6}$ and Wei Chen ${ }^{1,3,6,7}$ (D) \\ ${ }^{1}$ State Key Laboratory of Food Science and Technology, Jiangnan University, Wuxi, Jiangsu 214122, China \\ ${ }^{2}$ State Key Laboratory of Dairy Biotechnology, Shanghai Engineering Research Center of Dairy Biotechnology, Dairy Research Institute, \\ Bright Dairy and Food Co., Ltd., Shanghai 200436, China \\ ${ }^{3}$ School of Food Science and Technology, Jiangnan University, Wuxi, Jiangsu 214122, China \\ ${ }^{4}$ (Yangzhou) Institute of Food Biotechnology, Jiangnan University, Yangzhou 225004, China \\ ${ }^{5}$ Key Laboratory of Dairy Biotechnology and Bioengineering, Inner Mongolia Agricultural University, Hohhot 010018, China \\ ${ }^{6}$ National Engineering Research Centre for Functional Food, Wuxi, Jiangsu 214122, China \\ ${ }^{7}$ Beijing Innovation Centre of Food Nutrition and Human Health, Beijing Technology and Business University, Beijing 100048, China
}

\section{ABSTRACT}

The ability to use lactose is critical for the application of Streptococcus thermophilus in fermented dairy products. Most studies have evaluated the use of lactose of $S$. thermophilus by measuring lactose utilization, but its correlation with $\beta$-galactosidase and urease has rarely been investigated. In this study, 10 strains of $S$. thermophilus isolated from fermented yak milk exhibited a diversity of $\beta$-galactosidase and urease activities, growth, and acid production in de Man, Rogosa, and Sharpe-lactose. Among the strains, 15G5 possessed the highest $\beta$-galactosidase activity and showed the highest cell growth, lactic acid production, and titratable acidity during fermentation. In contrast, 7G10, with the weakest $\beta$-galactosidase activity, produced the lowest lactic acid content and change in titratable acidity. Further investigation indicated that $\beta$-galactosidase activity of $S$. thermophilus showed significant positive correlations with the growth of cell densities, the production of lactic acid, and titratable acidity, and urease activity of $S$. thermophilus showed a significant correlation with the use of lactose and the production of lactic acid and acetaldehyde. These findings suggest that the differences of $\beta$-galactosidase and urease activities are essential for the performance in the lactose metabolism, growth, and acid production of S. thermophilus, providing new insights into strain selection and application.

Key words: Streptococcus thermophilus, $\beta$-galactosidase, urease, fermentation characteristics

Received May 23, 2019.

Accepted September 18, 2019.

*Corresponding authors: liuzhenmin@brightdairy.com and liuxm@ jiangnan.edu.cn

\section{Short Communication}

Streptococcus thermophilus, which is commonly used in the dairy industry, has a limited capacity for carbohydrate utilization and prefers lactose to other sugars as its primary carbon and energy source (Iyer et al., 2010). The critical factor in the selection of $S$. thermophilus for application in fermented milk is its ability to rapidly metabolize lactose and produce acids. Its other essential aspects include its urease activity, proteolytic activity, and exopolysaccharide production (Iyer et al., 2010; Wu et al., 2014; Yamauchi et al., 2019).

For S. thermophilus, lactose is generally transported by the permease system and hydrolyzed by $\beta$-galactosidase to yield glucose and galactose (Zourari et al., 1992; Iyer et al., 2010; Wu et al., 2015). Glucose is then catabolized primarily to lactic acid via pyruvate metabolism in homolactic fermentation. Besides lactic acid, secondary metabolites such as acetate, ethanol, diacetyl, and acetaldehyde may also be generated. On the other hand, galactose is generally metabolized weakly by $S$. thermophilus and is thus expelled into the medium (Mora et al., 2002; Vaillancourt et al., $2004,2008)$. Therefore, the activity of $\beta$-galactosidase is essential for the performance of $S$. thermophilus in fermented milk (Husain, 2010).

Unlike the general presence of $\beta$-galactosidase among lactic acid bacteria, urease is an enzyme that is present only in S. thermophilus (Mora et al., 2002, 2005), and is known for its ability to catalyze urea into ammonia and carbon dioxide (Yamauchi et al., 2019). However, there are conflicting views regarding the role of urease in yogurt fermentation. Yamauchi et al. (2019) observed that urease deficiency severely reduced acidification rates and bacterial counts in fermented milk and con- 
cluded that urease was important for the growth of $S$. thermophilus in milk. However, Pernoud et al. (2004) did not observe a significant delay in the acidification and growth of $S$. thermophilus RD672 in the presence of flurofamide, a urease inhibitor. Because few studies have investigated correlations among the activity of enzymes such as $\beta$-galactosidase and urease, and the lactose utilization and fermentation properties in $S$. thermophilus, we characterized the enzyme activities ( $\beta$-galactosidase and urease) of selected $S$. thermophilus and its performance in fermenting milk.

Ten S. thermophilus strains were investigated in this study, including 9 strains (1M2, 4M6, 5M2, 6G3, 7G10, 9G9, 10M5, 14M3, 15G5) isolated from traditional fermented yak milk collected in Sichuan Province, China, and 1 commercial strain C2 (STI-12, Chr. Hansen A/S, Hørsholm, Denmark). The S. thermophilus strains were in the de Man, Rogosa, and Sharpe (MRS)-lactose broth with $2 \%$ lactose as the sole carbon source and were incubated at $37^{\circ} \mathrm{C}$ for $12 \mathrm{~h}$ under aerobic conditions before the analysis. After washing with a saline solution, the bacteria were transferred into the fresh MRS-lactose medium to an initial concentration of 5 $\times 10^{6}$ cells $/ \mathrm{mL}$ to record their growth, acid production, and rate of lactose utilization during incubation at $37^{\circ} \mathrm{C}$ for $16 \mathrm{~h}$ under aerobic conditions (Giaretta et al., 2018; Yang et al., 2019). After $12 \mathrm{~h}$ of incubation, the urease and $\beta$-galactosidase activities of the strains were determined as previously described, with 1 unit of urease activity defined as the release of $1 \mu \mathrm{mol}$ of $\mathrm{NH}_{4}^{+}$ per min (Mora et al., 2005; Zotta et al., 2008; Wu and Shah, 2017). Similarly, the strains were resuspended in the $11 \%$ (wt/vol) reconstituted sterilized skim milk after pre-incubation as described above, and the fermentation characteristics, nonvolatile compounds, and volatile compounds of 6 strains (1M2, 4M6, 6G3, 7G10, 15G5, and C2) were further analyzed during fermentation at $42^{\circ} \mathrm{C}$, with a final $\mathrm{pH}$ of 4.7 (Settachaimongkon et al., 2014; Zhao et al., 2016). Data presented are the average of 3 independent experiments. Pearson analysis was used to characterize the correlation of urease and $\beta$-galactosidase activities of the strains with microbial growth, lactose use, and volatile profile of the fermented milk. One-way ANOVA was performed using IBM SPSS Statistics version 24 (IBM Corp., Armonk, NY). Duncan's test was applied and a $P$-value of less than 0.05 was considered to indicate statistical significance.

Figure 1 shows the growth, acid production, and activities of urease and $\beta$-galactosidase of the selected strains. The 10 strains showed similar trends in growth in MRS-lactose, with variations in the growth rate (Figure 1A). The 9 S. thermophilus isolates from traditional fermented yak milk showed a higher growth rate in the MRS-lactose medium than $\mathrm{C} 2$. In contrast, no dramatic differences in acid production ability were observed among the strains (Figure 1B), and the acid production rates of the strains slowed after around $10 \mathrm{~h}$ of incubation, with a final $\mathrm{pH}$ around 4.5 to 4.7 .

Figures $1 \mathrm{C}$ and $1 \mathrm{D}$ show the results of the urease and $\beta$-galactosidase activities and each strain displayed 2 these activities. Variations in urease activity were observed among the strains; 6 of the 10 strains showed urease activity of greater than $400 \mathrm{U} / \mathrm{g}$, including C2, and the 7G10 strain showed the lowest urease activity $(109 \pm 14.14 \mathrm{U} / \mathrm{g} ; \pm \mathrm{SD})$ among the $10 \mathrm{~S}$. thermophilus isolates. Previous studies showed that urease activity exhibited dramatic differences in S. thermophilus from 2.4 to $510 \mathrm{U} / \mathrm{g}$ (Mora et al., 2005; Zotta et al., 2008). Zotta et al. (2008) reported that S. thermophilus Y3 had the lowest urease activity $(2.4 \mathrm{U} / \mathrm{g})$ in modified MRS broth, which increased to approximately $140 \mathrm{U} / \mathrm{g}$ with the addition of $5 \mathrm{~g} / \mathrm{L}$ urea. Urease activity of $S$. thermophilus DSM $20167^{\mathrm{T}}$ could reach $510 \mathrm{U} / \mathrm{g}$ in M17 broth containing $2 \%$ lactose when $\mathrm{pH}$ was controlled at 6.0 (Mora et al., 2005). It is clear that the culture medium affects the urease activity of $S$. thermophilus; therefore, such factors need to be considered for comparison among strains.

Unlike urease, $\beta$-galactosidase is widely distributed among lactic acid bacteria and is essential for hydrolyzing lactose in dairy products (Rhimi et al., 2010). The $\beta$-galactosidase activity varied significantly among the 10 strains (Figure 1D). The strain 15G5 showed the highest $\beta$-galactosidase activity $(870.94 \pm 7.40$ Miller units), followed by $\mathrm{C} 2$ and 9G9, and 7G10 showed the lowest $\beta$-galactosidase activity.

To further investigate the correlation of urease and $\beta$-galactosidase activities with the performance of $S$. thermophilus in fermented milk, 6 strains (1M2, 4M6, 15G5, C2, 6G3, and 7G10) with various urease and $\beta$-galactosidase activities were fermented in skim milk. Among these 6 strains, 1M2, 4M6, 15G5, and C2 possessed relatively high urease and $\beta$-galactosidase activities, and 7G10 and 6G3 displayed relatively low urease and $\beta$-galactosidase activities.

Figures $2 \mathrm{~A}$ and $2 \mathrm{~B}$ show the changes in viable cell counts, $\mathrm{pH}$ values, and titratable acidity in the fermented milk with various $S$. thermophilus strains. Half of the strains (1M2, 6G3, and 7G10) reached maximal cell counts at $2 \mathrm{~h}$, whereas it took $4 \mathrm{~h}$ for the other 3 strains (4M6, 15G5, and C2) to reach maximal growth. Our results were consistent with previous reports (Ren et al., 2015; Zha et al., 2015), confirming S. thermophilus as the most rapid growth species among LAB in milk. Differences in the acid production ability were observed among the strains, and the fermented milk incubated with 1M2, 6G3, and 7G10 showed slower acidification rates and increases in titratable acidity. 

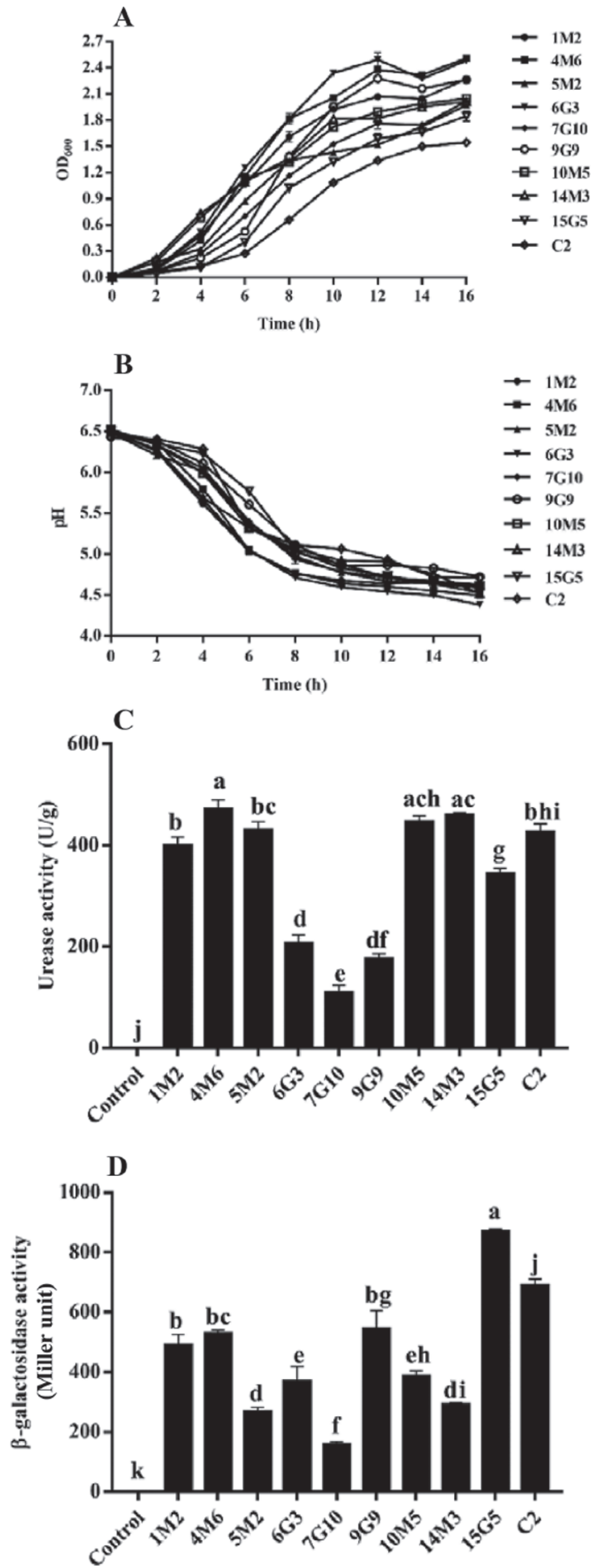

Figure 1. The results of growth (A), $\mathrm{pH}$ value (B), urease activity (C), and $\beta$-galactosidase activity (D) of Streptococcus thermophilus strains in de Man, Rogosa, and Sharpe (MRS)-lactose during fermentation at $37^{\circ} \mathrm{C}$. Growth and $\mathrm{pH}$ curves were analyzed, and urease and $\beta$-galactosidase activities of the strains were determined after $12 \mathrm{~h}$ of incubation in MRS-lactose. Column bars with no letters (a-k) in common are significantly different at $P<0.05$. The fresh medium without inoculation of $S$. thermophilus served as the negative control. Results are expressed as the means and SD of 3 independent analyses. $\mathrm{OD}_{600}$ $=$ optical density at $600 \mathrm{~nm}$.
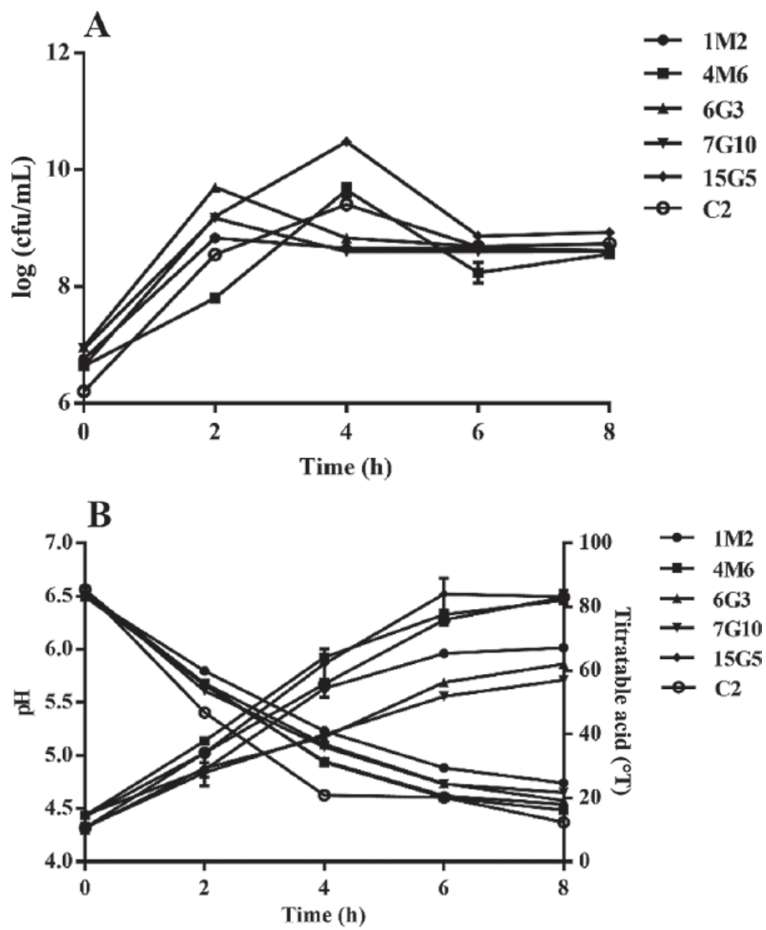

C

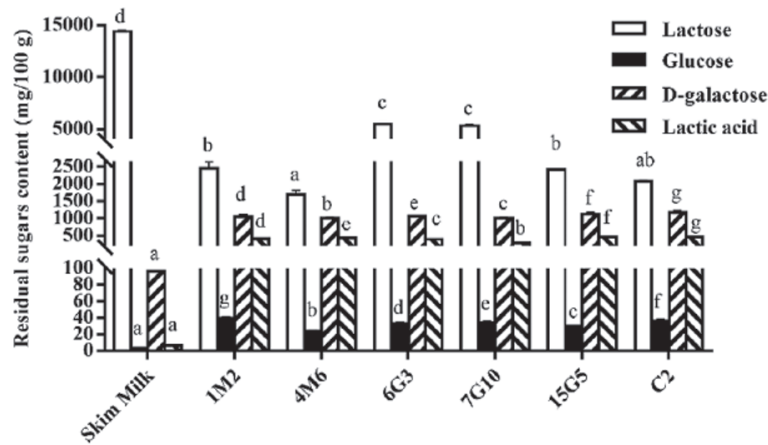

D

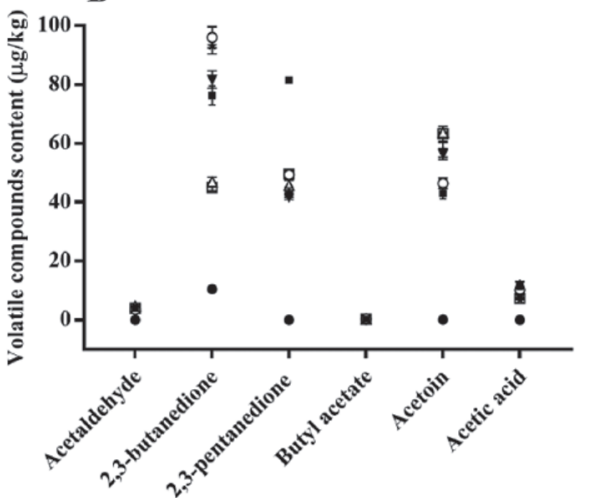

- Skim Milk

$1 \mathrm{M2}$

$\triangle \quad 4 \mathrm{M6}$

- $6 \mathrm{G3}$

* $7 \mathrm{G10}$

15G5

- $\mathrm{C} 2$

Figure 2. The results of growth (A) and acid production (B) of Streptococcus thermophilus in fermented skim milk over $8 \mathrm{~h}$, major sugar contents after $8 \mathrm{~h}$ of inoculation at $42^{\circ} \mathrm{C}(\mathrm{C})$, and volatile compounds content after $8 \mathrm{~h}$ of inoculation at $42^{\circ} \mathrm{C}(\mathrm{D})$. Column bars with no letters $(\mathrm{a}-\mathrm{g})$ in common are significantly different at $P<0.05$. Skim milk served as the negative control. Results are expressed as the means and SD of 3 independent analyses. 
The changes in the major sugar contents and volatile compounds of the samples after $8 \mathrm{~h}$ of incubation at $42^{\circ} \mathrm{C}$ are shown in Figures $2 \mathrm{C}$ and 2D. The lactose content decreased significantly, with increases in the content of galactose, glucose, and lactic acid during fermentation. Strains 1M2, 4M6, 15G5, and C2 consumed about 82 to $89 \%$ of the lactose after fermentation for $8 \mathrm{~h}$, whereas about $62 \%$ of the lactose was consumed by $6 \mathrm{G} 3$ and $7 \mathrm{G} 10$, the 2 strains with the lowest $\beta$-galactosidase activities, thus confirming the role of $\beta$-galactosidase activity in the use of lactose. Moreover, the glucose content was lower than that of galactose after fermentation in all 6 strains, revealing that the $S$. thermophilus strains have a preference for the use of glucose over that of galactose. Variation in the galactose content was also observed among the 6 strains. Nevertheless, although 6G3 and 7G10 had higher residual lactose than the other stains, no dramatic differences in the galactose content were observed among the strains, likely due to the higher galactose metabolism of 1M2, 4M6, 15G5, and C2. Similarly, significant differences were also revealed in lactic acid production. For the 2 strains with weak $\beta$-galactosidase and urease activities, 7G10 showed the lowest lactic acid production $(280.92 \pm 9.73$ $\mathrm{mg} / 100 \mathrm{~g})$, followed by $6 \mathrm{G} 3(398.86 \pm 11.73 \mathrm{mg} / 100 \mathrm{~g})$.

Figure $2 \mathrm{D}$ presents the concentration of major volatile compounds after fermentation, including acetaldehyde, 2,3-butanedione, 2,3-pentanedione, butyl acetate, acetoin, and acetic acid. Dramatic differences in the levels of 2,3-butanedione, 2,3-pentanedione, and acetoin were recorded among the 6 fermented samples. The 2,3-butanedione and 2,3-pentanedione were the most abundant in the samples of $15 \mathrm{G} 5(96.03 \pm 3.55$ $\mu \mathrm{g} / \mathrm{kg})$ and $\mathrm{C} 2(81.40 \pm 0.17 \mu \mathrm{g} / \mathrm{kg})$, and the acetoin content was the highest $(4.71 \pm 0.04 \mu \mathrm{g} / \mathrm{kg})$ in the sample of $4 \mathrm{M} 6$.

Figure 3 shows the correlations between the enzymatic activity ( $\beta$-galactosidase and urease) of the strains and their performance and lactose metabolism in fermented milk. First, $\beta$-galactosidase activity showed significant positive correlations $(P<0.05)$ with the growth of cell densities, the production of lactic acid, and titratable acidity. Among the 6 strains, 15G5 possessed the highest $\beta$-galactosidase activity ( $870.94 \pm 7.40$ Miller units) and showed the highest cell growth of $3.85 \pm 0.04 \mathrm{cfu} /$ $\mathrm{mL}$ (minimum 6.64; maximum 10.48), lactic acid production, and titratable acidity during fermentation. In contrast, 7G10, with the weakest $\beta$-galactosidase activity, produced the lowest lactic acid content and change in titratable acidity. Previous studies have shown that the $\beta$-galactosidase hydrolysis of lactose stimulates the growth rate of the starter cultures and decreases the coagulation time, simultaneously facilitating greater lac- tic acid production in fermented milk (Hsu et al., 2005; Nagaraj et al., 2009). In this study, the $\beta$-galactosidase activity of $S$. thermophilus showed a correlation with titratable acidity via lactic acid production and no correlation with acetic acid, which indicates that $\beta$-galactosidase activity may have a greater effect on the glycolysis pathway than on the pentose phosphate pathway in selected $S$. thermophilus. No correlation was observed between $\beta$-galactosidase activity and lactose consumption, indicating that the use of lactose involves additional factors other than $\beta$-galactosidase activity, such as substrate uptake or nitrogen metabolism (Wu et al., 2015; Arioli et al., 2017). Furthermore, the correlation between galactose content and cell counts revealed that galactose metabolism might also contribute to the growth of $S$. thermophilus in fermented milk, although $S$. thermophilus is known for the inhibition of galactose metabolism in the presence of lactose (Hutkins and Morris, 1987).

In contrast, the urease activity of $S$. thermophilus has shown a significant correlation with lactose use and the production of lactic acid (Pernoud et al., 2004; Arioli et al., 2010; Mora et al., 2013). Strain 4M6, with the highest urease activity $(471 \pm 18.38 \mathrm{U} / \mathrm{g})$, consumed the most lactose $(12,682.25 \pm 111.89 \mathrm{mg} / 100 \mathrm{~g})$ and generated the most lactic acid $(428.14 \pm 8.94 \mathrm{mg} / 100$ g) during fermentation. Although the physiological role of urease in S. thermophilus has not been completely understood, most studies have showed that urease is a crucial factor for $S$. thermophilus when grown alone or in combination with Lactobacillus bulgaricus (Pernoud et al., 2004; Arioli et al., 2010; Mora et al., 2013). Urea hydrolysis increases the catabolic efficiency of $S$. thermophilus by modulating the intracellular $\mathrm{pH}$ and increasing the activity of $\beta$-galactosidase, glycolytic enzymes, and lactate dehydrogenase. Urease activity is stimulated when the milk $\mathrm{pH}$ is weakly acidic $(\mathrm{pH}$ 5.8-6; Mora et al., 2005), thereby optimizing the activity of the glycolytic enzymes (Arioli et al., 2010). This important characteristic increases the fermentative capacity of $S$. thermophilus and leads to rapid growth (Pernoud et al., 2004) and an increased acidification rate in milk. Our results showing that urease activity of $S$. thermophilus may facilitate their lactose use and lactic acid production are consistent with previous research (Arioli et al., 2010, 2017). Acetaldehyde, the major aromatic compound in yogurt, also showed a positive relationship with urease activity, suggesting that an increase in urease activity may promote pyruvate metabolism and the formation of lactic acid and acetaldehyde. However, because no correlation was observed between urease activity and other volatiles such as 2,3-butanedione, 2,3-pentanedione, and acetoin, 


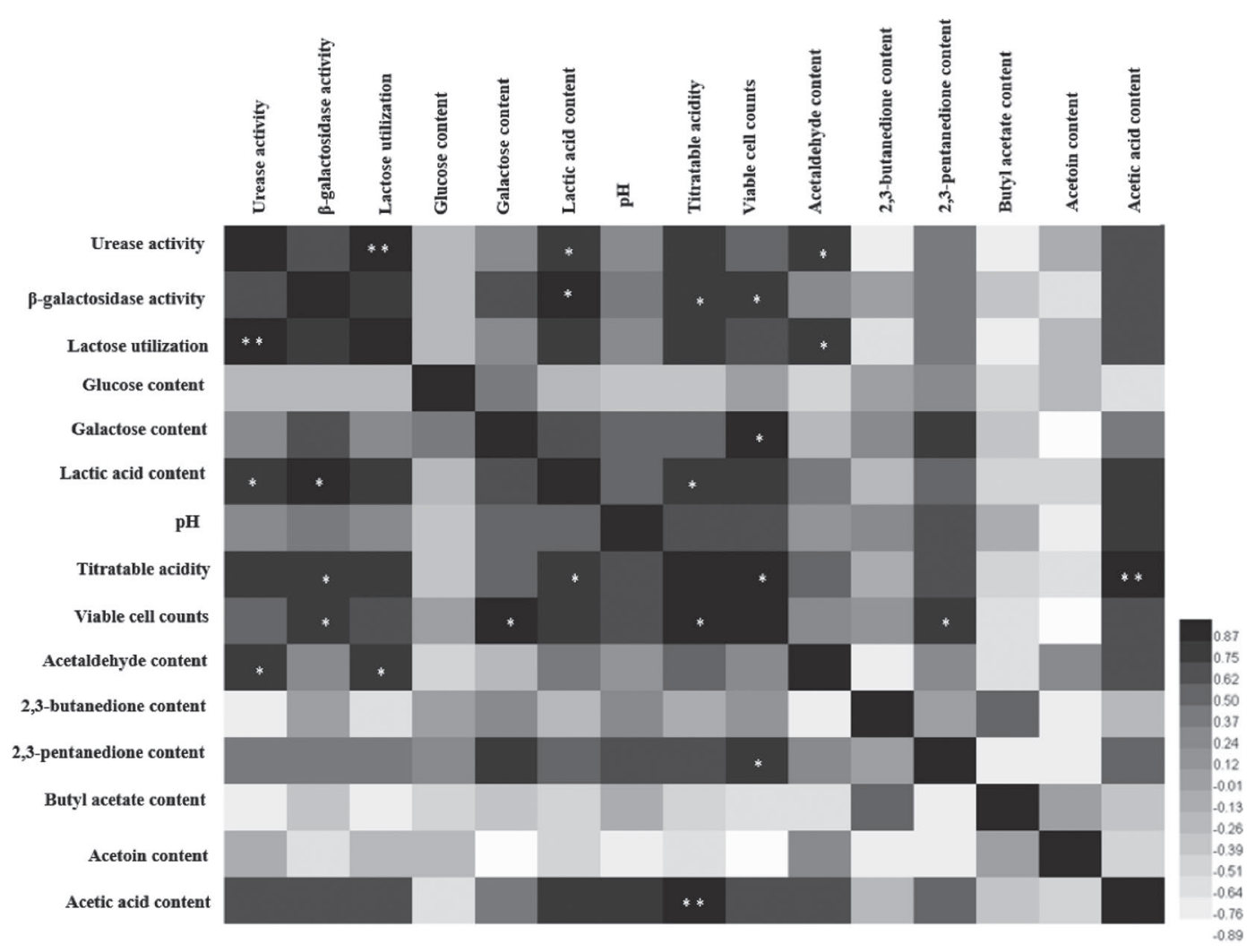

Figure 3. Pearson analysis of enzymatic activity ( $\beta$-galactosidase and urease), fermentation performance ( $\mathrm{pH}$, titration acidity, and viable cell counts), lactose metabolism (lactose utilization, the content of glucose, galactose, and lactic acid), and volatile compounds (acetaldehyde, 2,3-butanedione, 2,3-pentanedione, butyl acetate, acetoin, and acetic acid) of Streptococcus thermophilus in fermented milk after 8 h of fermentation. ${ }^{*} P<0.05$ and ${ }^{* *} P<0.01$ mean statistically significant differences within indicators. The $\mathrm{pH}$, titration acidity, and viable cell counts refer to the maximal change during $8 \mathrm{~h}$ of fermentation, respectively.

further investigation with related enzymatic activities is needed to fully understand the role of urease in the metabolism of $S$. thermophilus.

To conclude, this study focused on the role of lactose metabolism of $S$. thermophilus in fermentation of milk and found that $\beta$-galactosidase activity showed a significant positive correlation with the growth of cell densities, the production of lactic acid, and titratable acidity. Urease activity of $S$. thermophilus showed a significant correlation with the use of lactose and the production of lactic acid and acetaldehyde.

\section{ACKNOWLEDGMENTS}

The present research work was supported by the National Natural Science Foundation of China (no. 31871829), Agricultural Science and Technology Innovation Fund of Jiangsu Province [CX(17)1005], National First-Class Discipline Program of Food Science and Technology (JUFSTR20180102, China), the Fundamental Research Funds for the Central Universities (JUSRP51903B, China), and Collaborative Innovation
Centre of Food Safety and Quality Control in Jiangsu Province (China).

\section{REFERENCES}

Arioli, S., G. Della Scala, M. C. Remagni, M. Stuknyte, S. Colombo, S. Guglielmetti, I. De Noni, E. Ragg, and D. Mora. 2017. Streptococcus thermophilus urease activity boosts Lactobacillus delbruecki ssp. bulgaricus homolactic fermentation. Int. J. Food Microbiol. 247:55-64. https://doi.org/10.1016/j.ijfoodmicro.2016.01.006.

Arioli, S., E. Ragg, L. Scaglioni, D. Fessas, M. Signorelli, M. Karp, D. Daffonchio, I. De Noni, L. Mulas, M. Oggioni, S. Guglielmetti, and D. Mora. 2010. Alkalizing reactions streamline cellular metabolism in acidogenic microorganisms. PLoS One 5:e15520.

Giaretta, S., L. Treu, V. Vendramin, V. Da Silva Duarte, A. Tarrah, S. Campanaro, V. Corich, and A. Giacomini. 2018. Comparative transcriptomic analysis of Streptococcus thermophilus TH1436 and TH1477 showing different capability in the use of galactose. Front. Microbiol. 9. https://doi.org/10.3389/fmicb.2018.01765.

Hsu, C. A., R. C. Yu, and C. C. Chou. 2005. Production of $\beta$-galactosidase by Bifidobacteria as influenced by various culture conditions. Int. J. Food Microbiol. 104:197-206.

Husain, Q. 2010. Beta galactosidases and their potential applications: A review. Crit. Rev. Biotechnol. 30:41-62. https://doi.org/10 $.3109 / 07388550903330497$.

Hutkins, R. W., and H. A. Morris. 1987. Carbohydrate metabolism by Streptococcus thermophilus: A review. J. Food Prot. 50:876-884. https://doi.org/10.4315/0362-028X-50.10.876. 
Iyer, R., S. K. Tomar, T. Uma Maheswari, and R. Singh. 2010. Streptococcus thermophilus strains: Multifunctional lactic acid bacteria. Int. Dairy J. 20:133-141. https://doi.org/10.1016/j.idairyj.2009.10 .005 .

Mora, D., S. Arioli, and C. Compagno. 2013. Food environments select microorganisms based on selfish energetic behavior. Front. Microbiol. 4:348.

Mora, D., M. G. Fortina, C. Parini, G. Ricci, M. Gatti, G. Giraffa, and P. L. Manachini. 2002. Genetic diversity and technological properties of Streptococcus thermophilus strains isolated from dairy products. J. Appl. Microbiol. 93:278-287. https://doi.org/10.1046/j .1365-2672.2002.01696.x.

Mora, D., C. Monnet, C. Parini, S. Guglielmetti, A. Mariani, P. Pintus, F. Molinari, D. Daffonchio, and P. L. Manachini. 2005. Urease biogenesis in Streptococcus thermophilus. Res. Microbiol. 156:897903. https://doi.org/10.1016/j.resmic.2005.04.005.

Nagaraj, M., B. Sharanagouda, H. Manjunath, and M. Manafi. 2009. Standardization of different levels of lactose hydrolysis in the preparation of lactose hydrolyzed yoghurt. Majallah-i Tahqiqat-i Dampizishki-i Iran 10:132-136.

Pernoud, S., C. Fremaux, A. Sepulchre, G. Corrieu, and C. Monnet. 2004. Effect of the metabolism of urea on the acidifying activity of Streptococcus thermophilus. J. Dairy Sci. 87:550-555. https://doi .org/10.3168/jds.S0022-0302(04)73196-3.

Ren, Y., W. Liu, and H. Zhang. 2015. Identification of coccoidal bacteria in traditional fermented milk products from Mongolia, and the fermentation properties of the predominant species, Streptococcus thermophilus. Korean J. Food Sci. Anim. Resour. 35:683-691. https://doi.org/10.5851/kosfa.2015.35.5.683.

Rhimi, M., A. Boisson, M. Dejob, S. Boudebouze, E. Maguin, R. Haser, and N. Aghajari. 2010. Efficient bioconversion of lactose in milk and whey: Immobilization and biochemical characterization of a beta-galactosidase from the dairy Streptococcus thermophilus LMD9 strain. Res. Microbiol. 161:515-525. https://doi.org/10 $.1016 /$ j.resmic.2010.04.011

Settachaimongkon, S., M. J. R. Nout, E. C. A. Fernandes, K. A. Hettinga, J. M. Vervoort, T. C. M. van Hooijdonk, M. H. Zwietering, E. J. Smid, and H. J. F. van Valenberg. 2014. Influence of different proteolytic strains of Streptococcus thermophilus in co-culture with Lactobacillus delbrueckii subsp bulgaricus on the metabolite profile of set-yoghurt. Int. J. Food Microbiol. 177:29-36. https://doi.org/ 10.1016/j.ijfoodmicro.2014.02.008.

Vaillancourt, K., N. Bedard, C. Bart, M. Tessier, G. Robitaille, N. Turgeon, M. Frenette, S. Moineau, and C. Vadeboncoeur. 2008. Role of galK and galM in galactose metabolism by Streptococcus thermophilus. Appl. Environ. Microbiol. 74:1264-1267. https://doi .org/10.1128/AEM.01585-07.

Vaillancourt, K., J. D. LeMay, M. Lamoureux, M. Frenette, S. Moineau, and C. Vadeboncoeur. 2004. Characterization of a galac- tokinase-positive recombinant strain of Streptococcus thermophilus. Appl. Environ. Microbiol. 70:4596-4603. https://doi.org/10.1128/ AEM.70.8.4596-4603.2004.

Wu, Q., C. K. W. Cheung, and N. P. Shah. 2015. Towards galactose accumulation in dairy foods fermented by conventional starter cultures: Challenges and strategies. Trends Food Sci. Technol. 41:2436. https://doi.org/10.1016/j.tifs.2014.08.010.

Wu, Q., and N. P. Shah. 2017. The potential of species-specific tagatose-6-phosphate (T6P) pathway in Lactobacillus casei group for galactose reduction in fermented dairy foods. Food Microbiol. 62:178-187. https://doi.org/10.1016/j.fm.2016.10.027.

Wu, Q., H. M. Tun, F. C. Leung, and N. P. Shah. 2014. Genomic insights into high exopolysaccharide-producing dairy starter bacterium Streptococcus thermophilus ASCC 1275. Sci. Rep. 4. https: //doi.org/10.1038/srep04974.

Yamauchi, R., E. Maguin, H. Horiuchi, M. Hosokawa, and Y. Sasaki. 2019. The critical role of urease in yogurt fermentation with various combinations of Streptococcus thermophilus and Lactobacillus delbrueckii ssp. bulgaricus. J. Dairy Sci. https://doi.org/10.3168/ jds.2018-15192.

Yang, Y., N. Li, Y. Jiang, Z. Liu, X. Liu, J. Zhao, H. Zhang, and W. Chen. 2019. Short communication: Enzymatic perspective of galactosidases reveals variations in lactose metabolism among Lactococcus lactis strains. J. Dairy Sci. 102:6027-6031. https://doi.org/ 10.3168/jds.2018-15973.

Zha, M., J. Yu, Y. Zhang, H. Wang, N. Bai, Y. Qin, D. Liangliang, W. Liu, H. Zhang, and M. Bilige. 2015. Study on Streptococcus thermophilus isolated from Qula and associated characteristic of acetaldehyde and diacetyl in their fermented milk. J. Gen. Appl. Microbiol. 61:50-56. https://doi.org/10.2323/jgam.61.50.

Zhao, N., C. Zhang, Q. Yang, Z. Guo, B. Yang, W. Lu, D. Li, F. Tian, X. Liu, H. Zhang, and W. Chen. 2016. Selection of taste markers related to lactic acid bacteria microflora metabolism for Chinese traditional Paocai: A gas chromatography-mass spectrometrybased metabolomics approach. J. Agric. Food Chem. 64:24152422. https://doi.org/10.1021/acs.jafc.5b05332.

Zotta, T., A. Ricciardi, R. Rossano, and E. Parente. 2008. Urease production by Streptococcus thermophilus. Food Microbiol. 25:113119. https://doi.org/10.1016/j.fm.2007.07.001.

Zourari, A., J. P. Accolas, and M. J. Desmazeaud. 1992. Metabolism and biochemical characteristics of yogurt bacteria. A review. Lait 72:1-34. https://doi.org/10.1051/lait:199211.

\section{ORCIDS}

Xiaoming Liu @ \ttps://orcid.org/0000-0002-9128-2204

Wei Chen (1) https://orcid.org/0000-0003-3348-4710 